\title{
Instructional Theory and Technology for the New Paradigm of Education
}

\author{
Charles M. Reigeluth \\ Indiana University \\ reigelut@indiana.edu
}

\begin{abstract}
This article describes instructional theory that supports post-industrial education and training systems - ones that are customized and learner-centered, in which student progress is based on learning rather than time. The article describes universal methods of instruction, situational methods, core ideas of the post-industrial paradigm of instruction, the importance of and problems with task-based instruction, a vision of an instructional theory for postindustrial education and training, and the roles that may be played by the teacher, the learner, and technology in the new paradigm.
\end{abstract}

\section{Keywords:}

Instructional theory, post-industrial paradigm, task-basd instruction

Note: Significant portions of this article were published in Reigeluth (2011) and Reigeluth (2012). They are included here with permission of the publishers.

\section{Introduction}

One of the few things that practically everyone agrees on in both education and training is that people learn at different rates and have different learning needs. Yet our schools and training programs typically teach a predetermined, fixed amount of content in a set amount of time. Inevitably, slower learners are forced to move on before they have mastered the content, and they accumulate deficits in their learning that make it more difficult for them to learn related content in the future. Also, faster learners are bored to frustration and waste much valuable time waiting for the group to move on - a considerable squander of talent that our communities, companies, and society sorely need. A system that was truly designed to maximize learning would not force learners to move on before they had learned the current material, and it would not force faster learners to wait for the rest of the class.

Our current paradigm of education and training was developed during the industrial age. At that time, we could not afford to educate or train everyone to high levels, and we did not need to educate or train everyone to high levels. The predominant form of work was manual labor. In fact, if we educated everyone to high levels, few would be willing to work on assembly lines, doing mindless tasks over and over again. So, what we needed in the industrial age was an educational system that sorted students - one that separated the children who should do manual labor from the ones who should be managers or professionals. So the "less bright" students were flunked out, and the 
brighter ones were promoted to higher levels of education. This is why our schools use norm-referenced assessment systems rather than criterion-referenced assessment - to help sort the students. The same applied to our training systems. We must recognize that the main problem with our education and training systems is not the teachers or the students, it is the system - a system that is designed more for sorting than for learning (see Reigeluth, 1987; 1994, for examples).

Elsewhere, I have presented visions of what a post-industrial education system might be like - a system that is designed to maximize learning (Reigeluth, 1987; Reigeluth \& Garfinkle, 1994). With minor adaptations, that vision could be applied to our training systems as well. The purpose of this chapter is to describe instructional theory and technology that support such post-industrial education and training systems. In particular, it will:

- $\quad$ Describe universal methods of instruction based on Dave Merrill's "first principles".

- Discuss the importance of tailoring methods to particular situations and resolve the apparent contradiction with universal methods.

- Describe the "core ideas" of the post-industrial paradigm of instruction.

- Discuss the importance of, and problems with, task-based instruction (TBI),

- $\quad$ Present a vision of post-industrial instruction, complete with several major instructional strategies.

- Describe the roles that should be played by the "teacher", the learner, and technology in the new paradigm.

\section{Universal Methods of Instruction}

M. David Merrill has proposed that there is a set of five prescriptive instructional principles ("First Principles") that enhance the quality of instruction across all situations (Merrill, 2007, 2009). Those principles have to do with taskcenteredness, activation, demonstration, application, and integration. Briefly, they are as follows:

Task-Centered Principle

- $\quad$ Instruction should use a task-centered instructional strategy.

- Instruction should use a progression of increasingly complex whole tasks.

Demonstration Principle

- Instruction should provide a demonstration of the skill consistent with the type of component skill: kinds-of, how-to, and what-happens.

- Instruction should provide guidance that relates the demonstration to generalities.

- Instruction should engage learners in peer-discussion and peerdemonstration. 
- Instruction should allow learners to observe the demonstration through media that are appropriate to the content.

Application Principle

- Instruction should have the learner apply learning consistent with the type of component skill: kinds-of, how-to, and what-happens.

- $\quad$ Instruction should provide intrinsic or corrective feedback.

- Instruction should provide coaching, which should be gradually withdrawn to enhance application.

- Instruction should engage learners in peer-collaboration.

Activation Principle

- Instruction should activate relevant cognitive structures in learners by having them recall, describe, or demonstrate relevant prior knowledge or experience.

- Instruction should have learners share previous experience with each other.

- Instruction should have learners recall or acquire a structure for organizing new knowledge.

Integration Principle

- Instruction should integrate new knowledge into learners' cognitive structures by having them reflect on, discuss, or defend new knowledge or skills.

- Instruction should engage learners in peer-critique.

- Instruction should have learners create, invent, or explore personal ways to use their new knowledge or skill.

- Instruction should have learners publicly demonstrate their new knowledge or skill.

While these principles might apply universally to all instructional situations (situations involving aided learning), the specific methods by which each principle is implemented must vary from one situation to another for instruction to be of high quality (Reigeluth \& Carr-Chellman, 2009a). For example, for "Instruction should use a task-centered instructional strategy," the nature of the task-centered strategy may need to vary considerably from one situation to another. Similarly, for "Instruction should provide coaching," the nature of the coaching should vary considerably from one situation to another. So let's explore these variations, or "situationalities."

\section{Situational Methods of Instruction}

Principles and methods of instruction can be described on many levels of precision (Reigeluth \& Carr-Chellman, 2009b). For example, on the least precise level, Merrill states that instruction should provide coaching. On a highly precise level, one could state, "when teaching a procedure, if a learner skips a step during a performance of the procedure, the learner should be reminded of the step by asking the learner a question 
that prompts the learner to recognize the omission." When we provide more precision in a principle or method of instruction, we usually find that it needs to be different for different situations. Reigeluth (1999a) referred to the contextual factors that influence the effects of methods as "situationalities."

The challenge for instructional agents (and therefore instructional theorists) is to identify which situationalities are important for selecting each method. Furthermore, methods may be combined into a "package deal" that is made up of an interrelated and interdependent set of methods, in which case we need to identify which situationalities are important for selecting each "package" (set of methods).

Reigeluth and Carr-Chellman (2009a) propose that there are two major types of situationalities that call for fundamentally different sets of methods:

1. Situationalities based on different approaches to instruction (means), such as:
1.1. Role play
1.2. Synectics
1.3. Mastery learning
1.4. Direct instruction
1.5. Discussion
1.6. Conflict resolution
1.7. Peer learning
1.8. Experiential learning
1.9. Problem-based learning
1.10. Simulation-based learning

2. Situationalities based on different learning outcomes (ends), such as:

2.1. Knowledge

2.2. Comprehension

2.3. Application

2.4. Analysis

2.5. Synthesis

2.6. Evaluation

2.7. Affective development

2.8. Integrated learning (p. 58)

The chapters in Units 2 and 3 in Reigeluth and Carr-Chellman's (2009c) "Green Book 3" (Instructional-Design Theories and Models, Vol. III: Building a Common Knowledge Base) describe the "common knowledge base" for nine of those sets of methods.

In the remainder of this chapter, I provide a more holistic vision of what the postindustrial paradigm of instruction might be like. I start with "core ideas," followed by one possible vision, and finally roles of key players for this paradigm of instruction.

\section{Core Ideas for the Post-industrial Paradigm of Instruction}

The following are some core ideas for the post-industrial paradigm of instruction. They are presented as dichotomies to contrast them with the core ideas that characterize the industrial-age paradigm of instruction, but it should be understood that dichotomies are 
usually false, and post-industrial thinking is characterized more by "both-and" than "either-or".

Learning-focused vs. sorting focused. This core idea was discussed earlier in this chapter. All the following core ideas are chosen to support this central idea.

Learner-centered vs. teacher-centered instruction. McCombs and Whisler (1997) define learner centered as:

The perspective that couples a focus on individual learners (their heredity, experiences, perspectives, backgrounds, talents, interests, capacities, and needs) with a focus on learning (the best available knowledge about learning and how it occurs and about teaching practices that are most effective in promoting the highest levels of motivation, learning, and achievement for all learners). (p. 9)

To this I would add that the instructional methods are largely tailored to each learner and carried out by the learner rather than by the teacher. Learners also play a larger role in directing their own learning, including reflection on and in learning.

Learning by doing vs. teacher presenting. Most of a student's time is spent performing authentic tasks ${ }^{1}$, rather than listening to a teacher. Some talk about such task-based instruction in terms of the "student as worker" and the "teacher as manager," rather than the teacher as worker (Schlechty, 2002). Others call this the teacher as "guide on the side" rather than "sage on the stage." Some call it the constructivist approach to learning. The bottom line is that task-based instruction is active, learnercentered, and largely self-directed.

Attainment-based vs. time-based progress. Each student moves on to a new topic or competency when she or he has attained a standard of achievement, rather than when a certain amount of time has passed. A student is not forced to move on before attaining the standard and is allowed to move on as soon as the standard is attained. This avoids the huge waste of student time that exists in the industrial-age paradigm of education. This is a standards-based approach to education in the truest sense of the term. Mastery learning (Block, 1971; Bloom, 1968, 1981) was an early implementation of this core idea.

Customized vs. standardized instruction. The new paradigm offers customized rather than standardized learning experiences. This goes beyond attainment-based progress (which is customized pacing) to include customized content and customized methods. While there is a core of knowledge, skills, and attitudes that all students learn, there is considerable time for students to cultivate their particular talents, interests, and strengths. Also, Howard Gardner has shown that students differ in their profile of seven major kinds of intelligence and has argued that a student's strongest intelligences can be used most effectively as "entry points" for learning knowledge, skills, and attitudes (Gardner,

\footnotetext{
${ }^{1}$ Authentic tasks include problem-based, project-based, issue-based, case-based, and question-based learning, all of which are kinds of performance-based learning or learning by doing.
} 
1999). Methods are also customized for some other kinds of learner characteristics and preferences. Personal learning plans (different in important ways from IEPs $^{2}$ ) and learning contracts are valuable tools for customizing learning.

Criterion-referenced vs. norm-referenced testing. The two purposes of student assessment in the new paradigm are to guide student learning (formative assessment) and to certify student attainments (summative assessment). Norm-referenced assessment (another form of summative assessment) is no longer used. Formative assessment entails providing each student with immediate feedback on performance, with hints or other forms of guidance to help the student learn from mistakes. Summative assessment entails certifying when a student has reached the standard for any given attainment.

Collaborative vs. individual. In the workplace, most knowledge work is done in teams. Collaboration is important in work life, civic life, and family life. Therefore, students need experience in collaborating on small teams. Team-based learning on a task provides an excellent opportunity for students to develop their collaboration skills, but it also provides a valuable opportunity for students to learn from each other. Furthermore, it is strongly supported by social constructivism (Palincsar, 1998; Scardemalia \& Bereiter, 1996).

Enjoyable vs. unpleasant. In the age of knowledge work, lifelong learning is essential to our citizens' quality of life and to the health of our communities. Lifelong learning is greatly enhanced by love of learning. The industrial-age paradigm of education makes many students dislike learning, and it has turned the culture of our schools into one that devalues and derides students who excel in learning. That mindset and culture work against lifelong learning. Although lifelong learning has, for many years, been a buzzword in education, the industrial-age paradigm inherently impedes it. The postindustrial paradigm changes this by instilling a love of learning in students. This requires switching from extrinsic to intrinsic motivation. It also requires learning though authentic, engaging tasks, as is typically done in problem-based and projectbased learning.

These core ideas represent essential characteristics of post-industrial educational and training systems - ideas on a level of universality for post-industrial instruction as Merrill's First Principles of instruction are for all paradigms of instruction. However, the ways in which they are implemented are likely to vary considerably from one educational system to another. The following is a vision of instruction for one possible implementation of these core ideas.

\section{Task-Based Instruction}

Student engagement or motivation is key to learning. No matter how much work the teacher does, if the student doesn't work, the student doesn't learn. The quality and quantity of learning are directly proportional to the amount of effort the student devotes to learning. The industrial-age paradigm of education and training was based on

\footnotetext{
2 Individualized Education Plans or Individualized Education Programs, used mainly in special education.
} 
extrinsic motivation, with grades, study halls, detentions, and in the worst cases repeating a grade or flunking out.

In contrast, for a variety of reasons, intrinsic motivation is emphasized in the information-age paradigm. Reasons include the importance of lifelong learning and therefore of developing a love of learning, the decline of discipline in the home and school, and the lower effectiveness of extrinsic motivators now than 30 years ago.

To enhance intrinsic motivation, instructional methods should be learner-centered rather than teacher-centered. They should involve learning by doing, utilize tasks that are of inherent interest to the learner (which usually means they must be "authentic"), and offer opportunities for collaboration. This makes task-based instruction ${ }^{3}$ (TBI) particularly appropriate as a foundational instructional theory for the information-age paradigm of education and training.

Furthermore, given the importance of student progress being based on learning rather than on time, students progress at different rates and learn different things at any given time. This also lends itself well to TBI, because it is more learner-directed than teacherdirected.

It seems clear that TBI should be used prominently in the new paradigm of education and training. But there are problems with TBI. I explore those next.

\section{Problems with Task-Based Instruction}

In my own use of TBI, I have encountered four significant problems with it. Most TBI is collaborative or team-based, and typically the whole team is assessed on a final product. This makes it difficult to assess and ensure that all students have learned what was intended to learn. I have found that often one student on the team is a loafer and doesn't learn much at all. I have also found that teammates often work cooperatively rather than collaboratively, meaning they each perform different tasks and therefore learn different things. In my experience, it is rare for any student to have learned all that was intended. For a system in which student progress is based on learning, it is important to assess and ensure the learning of each and every student on the team. Yet it is rare for this to happen in TBI. This may not be as widespread a problem for higher levels of education, but it is a big problem for lower levels, because gaps in learning can make related future learning difficult and frustrating.

Second, the skills and competencies that we teach through TBI are usually ones that our learners will need to transfer to a broad range of situations, especially for complex cognitive tasks. However, in TBI learners typically use a skill only once or twice in the performance of the project. This makes it difficult for them to learn to use the skill in the full range of situations in which they are likely to need it in the future. Many skills

\footnotetext{
3 I use the term "task-based instruction" rather than "task-based learning" because the latter is what the learner does, whereas the former (TBI) is what the teacher or instructional system does to support the learning. Furthermore, I use the term TBI broadly to encompass instruction for project-based, problem-based, issue-based, case-based, and question-based (inquiry) learning.
} 
require extensive practice to develop them to a proficient or expert level, yet that rarely happens in TBI.

Third, some skills need to be automatized in order to free up the person's conscious cognitive processing for higher-level thinking required during performance of a task. TBI does not address this instructional need.

Finally, much learner time can be wasted during TBI - searching for information, doing busywork, repeating the use of skills that have already been mastered, and struggling to learn without sufficient guidance or support. It is often important, not just in corporate training, but also in K-12 and higher education, to get the most learning in the least amount of time. Such efficiency is not typically a hallmark of TBI.

Given these four problems with TBI - difficulty ensuring mastery, transfer, automaticity, and efficiency - does this mean we should abandon TBI and go with direct instruction, as Kirschner, Sweller and Clark (2006) propose? To quote a famous advertisement, "Not exactly." I now explore this issue.

\section{A Vision of the Post-industrial Paradigm of Instruction}

\section{Task and Instructional Spaces}

Imagine a small team of students working on an authentic task in a computer-based simulation (the "task space"). Soon they encounter a learning gap (knowledge, skills, understandings, values, attitudes, dispositions, etc.) that they need to fill to proceed with the task. Imagine that the students can "freeze" time and have a virtual mentor appear and provide customized tutoring "just in time" to develop that skill or understanding individually for each student (the "instructional space").

Research shows that learning a skill is facilitated to the extent that instruction tells the students how to do it, shows them how to do it for diverse situations, and gives them practice with immediate feedback, again for diverse situations (Merrill, 1983; Merrill, Reigeluth, \& Faust, 1979), so the students learn to generalize or transfer the skill to the full range of situations they will encounter in the real world. Each student continues to practice until she or he reaches the standard of mastery for the skill, much as in the Khan Academy (www.khanacademy.com). Upon reaching the standard, the student returns to the task space, where time is unfrozen, to apply what has been learned to the task and continue working on it until the next learning gap is encountered, and this doing-learning-doing cycle is repeated.

Well-validated instructional theories have been developed to offer guidance for the design of both the task space and the instructional space (see Reigeluth, 1999b; Reigeluth \& Carr-Chellman, 2009c, for examples). In this way we transcend the either/or thinking so characteristic of industrial-age thinking and move to both/and thinking, which is better suited to the much greater complexity inherent in the information age - we utilize instructional theory that combines the best of behaviorist, cognitivist, and constructivist theories and models. This theory pays attention to mastery of individual competencies, but it also avoids the fragmentation characteristic of many mastery learning programs in the past. 


\section{Team and Individual Assessment}

One of the problems with TBI as it is often implemented is that students are assessed on the quality of the team "product." This gives you no idea as to who has acquired which competencies. It also does not give you any indication of each student's ability to transfer those competencies to other situations where they may be needed. Team assessment is important, but you also need individual assessment, and the instructional space offers an excellent opportunity to meet this need. Like the task space, the instructional space is performance oriented. The practice opportunities (offered primarily in a computer simulation for immediate, customized feedback and authenticity) continue to be offered to a student until the student reaches the criterion for number of correct performances in a row that is required by the standard. Formative evaluation is provided immediately to the student on each incorrect performance, often in the form of hints that promote deeper cognitive processing and understanding. When automatization of a skill (Anderson, 1996) is important, there is also a criterion for speed of performance that must be met.

In this manner, student assessment is fully integrated into the instruction, and there is no waste of time in conducting a separate assessment. Furthermore, the assessment assures that each student has attained the standard for the full range of situations in which the competency will be needed.

When a performance cannot be done on a computer (e.g., a ballet performance), an expert has a hand-held device with a rubric for assessment, the expert fills in the rubric while observing the performance, provides formative evaluation when appropriate during the performance, allows the student to retry on a sub-standard performance when appropriate for further assessment, and the information is automatically fed into the computer system, where it is stored in the student's record and can be accessed by the student and other authorized people.

\section{Instructional Theory for the Task Space}

There is much validated guidance for the design of the task space, including universal and situational principles for the task space (see e.g., Barrows, 1986; Barrows \& Tamblyn, 1980; Duffy \& Raymer, 2010; Jonassen, 1997, 1999; Savery, 2009). They include guidance for selecting a good task at the right level of complexity, forming small groups, self-directed learning, what the teacher should do, how debriefing should be done, and more. Computer-based simulations are often highly effective for creating and supporting the task environment, but the task space could be comprised entirely of places, objects, and people in the real world (place-based learning), or it could be a combination of computer simulation and real-world environments. STAR LEGACY (Schwartz, Lin, Brophy, \& Bransford, 1999) is a good example of a computer-based simulation for the project space.

\section{Instructional Theory for the Instructional Space}

Selection of instructional strategies in the instructional space is primarily based on the type of learning (ends of instruction) involved (see Unit 3 in Reigeluth \& CarrChellman, 2009c). For memorization, drill and practice is most effective (Salisbury, 
1990), including chunking, repetition, prompting, and mnemonics. For application (skills), tutorials with generality, examples, practice, and immediate feedback are most effective (Merrill, 1983; Romiszowski, 2009). For conceptual understanding, connecting new concepts to existing concepts in student's cognitive structures requires the use of such methods as analogies, context (advance organizers), comparison and contrast, analysis of parts and kinds, and various other techniques based on the dimensions of understanding required (Reigeluth, 1983). For theoretical understanding, causal relationships are best learned through exploring causes (explanation), effects (prediction), and solutions (problem solving); and natural processes are best learned through description of the sequence of events in the natural process (Reigeluth \& Schwartz, 1989). These sorts of instructional strategies have been well researched for their effectiveness, efficiency, and appeal. And they are often best implemented through computer-based tutorials, simulations, and games.

Again, this is but one vision of the post-industrial paradigm of instruction. I encourage the reader to try to think of additional visions that meet the needs of the post-industrial era: principally intrinsic motivation, customization, attainment-based student progress, collaborative learning, and self-directed learning. To do so, it may be helpful to consider the ways that roles are likely to change in the new paradigm of instruction.

\section{Key Roles in the Post-industrial Paradigm of Instruction ${ }^{4}$}

Roles are likely to change for teachers, students, and technology. Each of these roles is briefly described next.

\section{New roles for teachers}

The teacher's role has changed dramatically in the new paradigm of instruction from the "sage on the stage" to the "guide on the side." I currently see three major roles involved in being a guide. First, the teacher is a designer of student work (Schlechty, 2002). The student work includes that which is done in both the task space and the instructional space. Second, the teacher is a facilitator of the learning process. This includes helping to develop a personal learning plan, coaching or scaffolding the student's learning when appropriate, facilitating discussion and reflection, and arranging availability of various human and material resources. Third, and perhaps most important in the public education sector, the teacher is a caring mentor, a person who is concerned with the full, well-rounded development of the student.

Teacher as designer, facilitator, and mentor are only three of the most important new roles that teachers serve, but not all teachers need to perform all the roles. Different kinds of teachers with different kinds and levels of training and expertise may focus on one or two of these roles (including students as teachers - see next section).

\footnotetext{
${ }^{4}$ Much of this section is based on Reigeluth (2009) and Reigeluth, Watson, S., Watson, W., Dutta, Chen, and Powell (2008).
} 


\section{New Roles for Students}

First, learning is an active process. The student must exert effort to learn. The teacher cannot do it for the student. This is why Schlechty (2002) characterizes the new paradigm as one in which the student is the worker, not the teacher, and that the teacher is the designer of the student's work.

Second, to prepare the student for lifelong learning, the teacher helps each student to become a self-directed and self-motivated learner. Students are self-motivated to learn from when they are born to when they first go to school. The industrial-age paradigm systematically destroys that self-motivation by removing all self-direction and giving students boring work that is not relevant to their lives. In contrast, the post-industrial system is designed to nurture self-motivation through self-direction and active learning in the context of relevant, interesting tasks. Student motivation is key to educational productivity and helping students to realize their potential. It also greatly reduces discipline problems, drug use, and much more.

Third, it is often said that the best way to learn something is to teach it. Students are perhaps the most under-utilized resource in our school systems. Furthermore, someone who has just learned something is often better at helping someone else learn it than is someone who learned it long ago. In addition to older students teaching slightly younger ones, peers can learn from each other in collaborative projects, and they can also serve as peer tutors.

Therefore, new student roles include student as worker, self-directed learner, and teacher.

\section{New Roles for Technology}

I currently see four main roles for technology to make the new paradigm of instruction feasible and cost-effective (Reigeluth \& Carr-Chellman, 2009c; Reigeluth et al., 2008). Each of these is described next for the public education sector, but the roles are equally relevant in higher education, corporate training, military training, and education and training in other contexts.

Record keeping for student learning. Attainment-based student progress requires a personal record of attainments for each student. Technology saves teachers huge amounts of time for this. In this role, technology replaces the current report card, and it has three parts. First, it has a Standards Inventory that contains both required educational standards (national, state, and local) and optional educational standards for access by the teacher, student, and parents. These standards are broken down to individual attainments and are displayed in a "domain map" format similar to that of the Khan Academy. Domain Theory (Bunderson, Wiley, \& McBride, 2009) is highly instrumental for designing this technological tool. It presents a list of attainments that should or can be learned, along with levels or standards or criteria at which each can be learned. Second, it has a Personal Attainments Inventory that contains a record of what each student knows. In essence, it maps each student's progress on the attainments listed in the Standards Inventory (and perhaps some that are not yet listed there). It shows when each attainment was reached, which ones are required, what the next 
required attainments are in each area, and links to evidence of each attainment (in the form of summary data and/or original artifacts). Third, it has a Personal Characteristics Inventory that keeps track of each student's characteristics that influence learning, such as learning styles, profile of multiple intelligences, special needs, student interests and goals, and major life events (Reigeluth \& Carr-Chellman, 2009c; Reigeluth et al., 2008).

Planning for student learning. The personal learning plan, or contract, could also be very difficult for teachers to develop for all of their students. Here, again, is a role that technology is ideally suited to play. It helps the student, parents, and teacher to (a) decide on long-term goals; (b) identify the full range of attainment options that are presently within reach for the student; (c) select from those options the ones that the student wants to pursue now (short-term goals), based on requirements, long-term goals, interests, opportunities, etc.; (d) identify or create tasks for attaining the short-term goals; (e) identify and match up with other students who are interested in doing the same tasks at the same time (if collaboration is desired or needed) and specify all teammates' roles; (f) specify the roles that the teacher, parent, and any other mentors might play in supporting the student in learning from the task; and (g) develop a contract that specifies goals, tasks, teams, student roles and responsibilities, parent and teacher roles, method of assessment, and the deadline for each task (Reigeluth et al., 2008).

Instruction for student learning. Trying to "instruct" 25 students who are learning different things at any point in time could be very difficult for teachers - if they had to be the instructional agent all the time, as is typical in the industrial-age paradigm. However, technology can introduce the task to a student (or small team) in the task space, provide instructional tools (such as simulations, tutorials, drill \& practice, research tools, communication tools, and learning objects) in the instructional space to support learning during the task (as described earlier), provide tools for monitoring and supporting student progress on the task, and even provide tools to help teachers and others develop new tasks and instructional tools. Technology can make all the above functions available to students any time and anywhere. Instructional theory is extremely important to guide the design of these tools (Reigeluth et al., 2008).

Assessment for (and of) student learning. Once more, conducting formative and summative assessments of students could be a nightmare for teachers, since students are not all taking a given test at the same time. And once again, technology can offer great relief. First, as mentioned earlier, assessment is integrated with instruction. The plentiful performance opportunities that are used to cultivate competencies are used for both formative and summative assessments. Second, the assessments present authentic tasks on which the students demonstrate their knowledge, understanding, and skill. Third, whether in a simulation or a tutorial or drill and practice, the technology is designed to evaluate whether or not the criterion was met on each performance and to provide formative feedback to the student immediately for the greatest impact. When the criteria for successful performance have been met on $x$ out of the last $y$ performances, the summative assessment is complete and the corresponding attainment is automatically checked off in the student's personal inventory of attainments. In the few cases where the technology cannot assess the performance, an observer has a handheld device with a rubric for assessment and personally provides the immediate 
feedback on student performances. The information from the handheld device is uploaded into the computer system, where it is placed in the student's personal inventory. Finally, technology provides tools to help teachers develop assessments and link them to the standards (Reigeluth et al., 2008).

Note that these four roles or functions are seamlessly integrated (Reigeluth \& CarrChellman, 2009c). The record-keeping tool provides information automatically for the planning tool. The planning tool identifies instructional tools that are available. The assessment tool is integrated into the instructional tool. And the assessment tool feeds information automatically into the record-keeping tool (Reigeluth et al., 2008; Watson, Lee, \& Reigeluth, 2007). In our earlier work we used the term "Learning Management System" for this comprehensive, personalized, integrated tool, but that term is often used to describe course management systems that are teacher-centered. Therefore, to avoid confusion, we have decided to call this the Personalized Integrated Educational System (PIES).

Also, please note that there are many other roles for the PIES (Reigeluth et al., 2008). These "secondary" roles include communications (email, blogs, web sites, discussion boards, wikis, whiteboards, instant messaging, podcasts, videocasts, etc.), PIES administration (offering access to information and authority to input information based on role and information type), general student data (student's address, parent/guardian information, mentor-teacher and school, student's location/attendance, health information), school personnel information (address, certifications and awards, location, assigned students, tools authored, student evaluations that they have performed, teacher professional development plan and records, repository of teaching tools, awards their students have received), and more.

It should be apparent that technology will play a crucial role in the success of the postindustrial paradigm of education. It will enable a quantum improvement in student learning, and likely at a lower cost per student per year than in the current industrial-age paradigm. Just as the electronic spreadsheet made the accountant's job quicker, easier, less expensive, and more enjoyable, so the PIES described here will make the teacher's job quicker, easier, less expensive, and more enjoyable. But instructional theory is sorely needed for technology to realize its potential contribution.

\section{Conclusion}

In the post-industrial world, we need to transform most of our educational and training systems from ones that are designed for sorting students to ones that are designed to maximize learning - from ones in which student progress is time-based to ones in which it is attainment-based. This transformation will require advances in both instructional theory and instructional technology.

Merrill's First Principles (task-centeredness, activation, demonstration, application, and integration) provide a good, albeit general, summary of the most important features for high quality instruction. For more detailed guidance, we must look at the "situationalities" that determine the ways in which instruction should differ from one situation to another. Research to date indicates that these are based primarily on 
differing means (different approaches to instruction) and differing ends (different learning outcomes or kinds of learning).

In addition, it is helpful to look at a more holistic vision of what the new paradigm of instruction might be like. I proposed that it will be characterized by the following core ideas: learning-focused, learner-centered, learning by doing, attainment-based progress, customized instruction, criterion-referenced testing, collaborative learning, and enjoyable learning. I then proposed a vision of instruction for one possible implementation of these core ideas. It describes: task and instructional spaces, team and individual assessment, instructional strategies for the task space, and instructional strategies for the instructional space.

Finally, I summarized a set of key roles for the new paradigm of instruction. New roles for teachers include: designer of student work, facilitator of the learning process, and caring mentor. New roles for students include: worker, self-directed learner, and teacher. Four major new roles were described for technology. First, record keeping for student learning includes offering a standards inventory, a personal attainments inventory, and a personal characteristics inventory. Second, planning for student learning includes helping the student, parents, and teacher to identify or decide on longterm goals, attainments currently within the student's reach, attainments to pursue in the next contract, tasks for learning those attainments, other students to work on a team, roles for the teacher and parents, and a contract. Third, instruction for student learning includes a wide variety of tools for both the task space and the instructional space. Finally, assessment for (and of) student learning is integrated with the instruction, uses authentic tasks and performances, certification of attainments and formative feedback.

While much instructional theory has been generated to guide the design of the new paradigm of instruction, much remains to be learned. We need to learn how to better address the strong emotional basis of learning (Greenspan, 1997), foster emotional and social development, and promote the development of positive attitudes, values, morals, and ethics, among other things. It is my hope that you, the reader, will rise to the challenge and help further advance the knowledge we need to greatly improve our ability to help every student reach his or her potential.

Article concluded in September 2012

Reigeluth, C. (2016). Instructional Theory and Technology for the New Paradigm of Education. RED, Revista de Educación a Distancia. Número 50.30 de septiembre de 2016. Consultado el (dd/mm/aaa) en http://www.um.es/ead/red/50 


\section{References}

Anderson, J. R. (1996). The architecture of cognition. Mahwah, NJ: Lawrence Erlbaum Associates.

Barrows, H. S. (1986). A taxonomy of problem-based learning methods. Medical Education, 20(6), 481-486. doi: 10.1111/j.1365-2923.1986.tb01386.x

Barrows, H. S., \& Tamblyn, R. M. (1980). Problem-based learning: An approach to medical education. New York: Springer.

Block, J. H. (1971). Mastery learning: Theory and practice. New York: Holt, Rinehart and Winston, Inc.

Bloom, B. S. (1968). Learning for mastery. Evaluation Comment, 1(1), 1-12.

Bloom, B. S. (1981). All our children learning. New York: McGraw-Hill.

Bunderson, C. V., Wiley, D. A., \& McBride, R. (2009). Domain Theory for instruction: Mapping attainments to enable learner-centered education. In C. M. Reigeluth \& A. A. Carr-Chellman (Eds.), Instructional-design theories and models: Building a common knowledge base (Vol. III, pp. 327-347). New York: Routledge.

Duffy, T. M., \& Raymer, P. L. (2010). A practical guide and a constructivist rationale for inquiry based learning. Educational Technology, 50(4), 3-15.

Gardner, H. E. (1999). Multiple approaches to understanding. In C. M. Reigeluth (Ed.), Instructional-design theories and models, vol. II: A new paradigm of instructional theory (pp. 69-89). Mahwah, NJ: Lawrence Erlbaum Associates.

Greenspan, S. I. (1997). The growth of the mind and the endangered origins of intelligence. Reading, MA: Addison-Wesley Publishing Company.

Jonassen, D. H. (1997). Instructional design models for well-structured and illstructured problem-solving learning outcomes. Educational Technology Research and Development, 45(1), 65-94.

Jonassen, D. H. (1999). Designing constructivist learning environments. In C. Reigeluth (Ed.), Instructional-Design Theories and Models (pp. 215-239). Mahwah, New Jersey: Lawrence Erlbaum.

Kirschner, P. A., Sweller, J., \& Clark, R. E. (2006). Why minimal guidance during instruction does not work: An analysis of the failure of constructivist, discovery, problem-based, experiential, and inquiry-based teaching. Educational Psychologist, 41(2), 75-86.

McCombs, B., \& Whisler, J. S. (1997). The learner-centered classroom and school: Strategies for increasing student motivation and achievement. San Francisco: Jossey-Bass Publishers.

Merrill, M. D. (1983). Component display theory. In C. M. Reigeluth (Ed.), Instructional-design theories and models: An overview of their current status. Hillsdale, NJ: Lawrence Erlbaum Associates.

Merrill, M. D. (2007). First principles of instruction: A synthesis. In R. A. Reiser \& J. V. Dempsey (Eds.), Trends and issues in instructional design and technology (2nd ed., pp. 62-71). Upper Saddle River, NJ: Merrill/Prentice-Hall. 
Merrill, M. D. (2009). First principles of instruction. In C. M. Reigeluth \& A. A. CarrChellman (Eds.), Instructional-design theories and models: Building a common knowledge base (Vol. III, pp. 41-56). New York: Routledge.

Merrill, M. D., Reigeluth, C. M., \& Faust, G. W. (1979). The Instructional Quality Profile: A curriculum evaluation and design tool. In H. F. O'Neil, Jr. (Ed.), Procedures for Instructional Systems Development. New York: Academic Press.

Palincsar, A. S. (1998). Social constructivist perspectives on teaching and learning. Annual Review of Psychology, 49, 345-375.

Reigeluth, C. M. (1983). Meaningfulness and Instruction: Relating What Is Being Learned to What a Student Knows. Instructional Science, v12 n3 p197-218 Oct 1983, 12(3).

Reigeluth, C. M. (1987). The search for meaningful reform: A third-wave educational system. Journal of Instructional Development, 10(4), 3-14.

Reigeluth, C. M. (1994). The imperative for systemic change. In C. M. Reigeluth \& R. J. Garfinkle (Eds.), Systemic change in education (pp. 3-11). Englewood Cliffs, NJ: Educational Technology Publications.

Reigeluth, C. M. (1999a). What is instructional-design theory and how is it changing? In C. M. Reigeluth (Ed.), Instructional-design theories and models: A new paradigm of instructional theory (Vol. II, pp. 5-29). Mahwah, NJ: Lawrence Erlbaum Associates.

Reigeluth, C. M. (2009). Instructional theory for education in the information age. In C. M. Reigeluth \& A. A. Carr-Chellman (Eds.), Instructional-design theories and models: Building a common knowledge base (Vol. III, pp. 387-399). New York: Routledge.

Reigeluth, C. M. (2011). An instructional theory for the post-industrial age. Educational Technology, 51(5), 25-29.

Reigeluth, C. M. (2012). Instructional theory and technology for a post-industrial world. In R. A. Reiser \& J. V. Dempsey (Eds.), Trends and issues in instructional design and technology (3rd ed., pp. 75-83). Boston: Pearson Education.

Reigeluth, C. M. (Ed.). (1999b). Instructional-design theories and models: A new paradigm of instructional theory (Vol. II). Mahwah, N.J.: Lawrence Erlbaum Associates.

Reigeluth, C. M., \& Carr-Chellman, A. A. (2009a). Situational principles of instruction. In C. M. Reigeluth \& A. A. Carr-Chellman (Eds.), Instructional-design theories and models: Building a common knowledge base (Vol. III, pp. 57-68). New York: Routledge.

Reigeluth, C. M., \& Carr-Chellman, A. A. (2009b). Understanding instructional theory. In C. M. Reigeluth \& A. A. Carr-Chellman (Eds.), Instructional-design theories and models: Building a common knowledge base (Vol. III, pp. 3-26). New York: Routledge.

Reigeluth, C. M., \& Carr-Chellman, A. A. (Eds.). (2009c). Instructional-design theories and models: Building a common knowledge base (Vol. III). New York: Routledge. 
Reigeluth, C. M., \& Garfinkle, R. J. (1994). Envisioning a new system of education. In C. M. Reigeluth \& R. J. Garfinkle (Eds.), Systemic Change in Education (pp. 59-70). Englewood Cliffs, NJ: Educational Technology Publications.

Reigeluth, C. M., \& Schwartz, E. (1989). An instructional theory for the design of computer-based simulations. Journal of Computer-Based Instruction, 16(1), 110.

Reigeluth, C. M., Watson, S. L., Watson, W. R., Dutta, P., Chen, Z., \& Powell, N. (2008). Roles for technology in the information-age paradigm of education: Learning management systems. Educational Technology, 48(6), 32-39.

Romiszowski, A. (2009). Fostering skill development outcomes. In C. M. Reigeluth \& A. A. Carr-Chellman (Eds.), Instructional-design theories and models: Building a common knowledge base (Vol. III, pp. 199-224). New York: Routledge.

Salisbury, D. F. (1990). Cognitive psychology and Its implications for designing drill and practice programs for computers. Journal of Computer-Based Instruction, 17(1), 23-30.

Savery, J. R. (2009). Problem-based approach to instruction. In C. M. Reigeluth \& A. A. Carr-Chellman (Eds.), Instructional-design theories and models: Building a common knowledge base (Vol. III, pp. 143-165). New York: Routledge.

Scardemalia, M., \& Bereiter, C. (1996). Computer support for knowledge-building communities. In T. Koschmann (Ed.), CSCL: Theory and practice of an emerging paradigm (pp. 249-268). Mahwah, NJ: Lawrence Erlbaum Assoc.

Schlechty, P. (2002). Working on the work. New York: John Wiley \& Sons.

Schwartz, D. L., Lin, X., Brophy, S., \& Bransford, J. D. (1999). Toward the development of flexibly adaptive instructional designs. In C. M. Reigeluth (Ed.), Instructional-design theories and models: A new paradigm of instructional theory (Vol. II, pp. 183-213). Mahwah, NJ: Lawrence Erlbaum.

Watson, W. R., Lee, S. K., \& Reigeluth, C. M. (2007). Learning management systems: An overview and roadmap of the systemic application of computers to education. In F. M. Neto \& F. V. Brasileiro (Eds.), Advances in Computer-Supported Learning (pp. 66-96). Hershey, PA: Information Science Publishing. 